\title{
GÉNERO, PODER Y LITERATURA EN LA ESPAÑA \\ CONTEMPORÁNEA
}

\author{
ENCARNA Alonso VALERO
}

Universidad de Granada

\begin{abstract}
This paper analyzes the images of power and the consecration mechanisms that can be found in the pathways of several political women in the first third of the 20th century in Spain. To that end, this work considers concepts like the idea of merit and the idea of exceptions creation, among others.

The construction of national feminine myths is also analyzed, giving a detailed overview about the utilization of music and literature as effective resources to conform those miths.

La imagen que nos ha llegado de las mujeres en los años 20 y principios de los 30 , tanto en sus representaciones gráficas como literarias (que estuvieron, por razones obvias, mayoritariamente hechas por hombres), se ha convertido en un referente que suele interpretarse como una imagen innovadora e incluso revolucionaria. No obstante, aunque se alude con frecuencia a la conciencia de libertad de las mujeres en las vanguardias, a la emancipación femenina y al rechazo del rol tradicional tras la irrupción de la 'mujer moderna', las relaciones entre los sexos están en ese periodo menos transformadas de lo que una observación superficial podría hacer creer. Y lo mismo ocurre en el ámbito político, donde necesariamente tendremos que volver los ojos al hablar del poder y su representación en la historia contemporánea. No se trata de negar radicalmente la dudosa movilización y acción colectiva (que tendría que ser típicamente política) de resistencia, orientada hacia reformas jurídicas y políticas (aunque sí existieron movimientos opuestos a la resignación que estimulan todas las visiones esencialistas, entre las que sin duda se cuenta el sexismo, y hubo en algunos ámbitos ciertas rupturas de los hábitos y rutinas); aunque se dieron las revueltas propias de los pequeños grupos de solidaridad y de apoyo mutuo, probablemente uno de los pasos fundamentales estaría en el compromiso iniciado en la acción política (y todo lo que lleva consigo: acción jurídica, etc). Se empezó ese camino, por mucho que en algunos casos se hiciese de maneras cuya lógica, presupuestos y eficacia puedan ser dudosos (los principios siempre son complicados), pero lo que difícilmente puede discutirse es que esa lucha estuvo o acabó sumergida con las
\end{abstract}


formas y normas del combate político en movimientos muchas veces ajenos a sus preocupaciones e intereses (o en los que éstos se encontraban muy diluidos): todos los partidos eran profundamente conservadores en materia de género.

De este modo, no podemos dejar de preguntarnos qué fue lo que hizo posible que en las primeras elecciones de la República (en las que las mujeres podían ser elegidas pero no votar) tres mujeres llegasen a ocupar un escaño de diputada (Margarita Nelken ${ }^{1}$, Clara Campoamor y Victoria Kent). En las dos elecciones posteriores, aumentó el número de mujeres que ocupaban un escaño (sólo una de ellas, Francisca Bohigas, de la CEDA, lo hizo representando a un partido conservador), lista a la que hay que añadir el nombre de la anarquista Federica Montseny ${ }^{2}$, ministra de Sanidad y Asistencia Social en plena Guerra Civil. Apenas es necesario aclarar que era la primera mujer que accedía a ese cargo.

Para explicar estos casos, así como la discusión sobre el voto femenino, es necesario dirigir la mirada a Europa y al amplio movimiento sufragista que había ido tomando forma tras la Primera Guerra Mundial, así como al propio desarrollo de los feminismos en el continente, pues a consecuencia de todo ello se crean determinadas estructuras de partido que permiten la introducción de mujeres en espacios que antes estaban vedados para ellas.

Así, en función de la idea de mérito, estaba abonándose el terreno para la producción de excepciones. Se hicieron concesiones en la dinámica de la permisividad relativa para esa creación de excepciones, manteniendo el viejo rigor para el conjunto ${ }^{3}$, pues la creación de excepciones es un elemento imprescindible para que las posiciones de liderazgo y poder sean percibidas como adquiridas o distribuidas en función del mérito (recordemos el concepto de 'mujer coartada' del que hablaron Simone de Beauvoir ${ }^{4}$ o Hannah Arendt ${ }^{5}$, entre otras). La

\footnotetext{
1 Veáse Margarita NELKEN, Las escritoras españolas, Barcelona, Labor, 1930, y, de la misma autora, [s.f.]. La condición social de la mujer, Madrid, CVS, 1975.

${ }^{2}$ Contamos con varias biografías de Federica Montseny, entre ellas Susanna TAVERA, Federica Montseny. La indomable (1905-1994), Madrid, Temas de Hoy, 2005; Irene LOZANO, Federica Montseny. Una anarquista en el poder, Madrid, Espasa-Calpe, 2004.

3 Amelia VALCÁRCEL, "Las filosofías políticas en presencia del feminismo", in: Celia AMORÓS (ed.), Feminismo y filosofía, Madrid, Síntesis, 2000, 123.

${ }^{4}$ En una entrevista, dijo: "Les féministes, aujourd'hui, refusent d'être des femmes-alibi, comme je l'étais. Elles ont raison, il faut lutter!', Alice SCHWARZER, Simone de Beauvoir aujourd'bui, París, Mercure de France, 1984, 72.

${ }^{5}$ Invitada en 1953 a la Universidad de Princenton para dictar los seminarios Christian Gauss, varios de los asistentes expresaron su satisfacción por el hecho de tener por primera vez a una mujer como conferenciante; lejos de sentirse halagada, Hannah Arendt respondió muy críticamente, haciendo notar su enojo por haber sido puesta en el papel de 'mujer coartada'. En una carta dirigida a Kurt Blumenfeld decía al respecto: "ilustré a esos honorables caballeros sobre lo que es una judía de excepción, y traté de dejarles muy claro que aquí me he sentido
} 
existencia de esos casos aislados es lo que permite, junto con otras variables, defender que un sistema es igualitario y meritocrático a pesar y después de todo.

Muchos son los mecanismos de consagración que muestran a los constituidos como élite, entre ellos la ocupación de un puesto destacado en un partido o la llegada al Parlamento. A su vez, existe una extensa serie de tácitas llamadas al orden, de distintos ritos institucionales que tienen un lugar fundamental y que en la problemática que nos ocupa adquieren una enorme importancia: entre otras cosas, buscan instaurar y fijar una separación no sólo entre los que ya han recibido la marca distintiva y los que todavía no lo han hecho, sino sobre todo entre los que son socialmente dignos de recibirla y los que están excluidos, entre ellos las mujeres.

Esto es así hasta el extremo de que, con respecto a la cuestión de la actuación de las mujeres en las discusiones sobre el voto femenino, habría que preguntarse qué categorías (y articuladas de qué manera) llevan a las mujeres a contribuir al reforzamiento de su exclusión de los lugares de los que están ya excluidas; como es sabido, algunas parlamentarias colaboraban, negándole a las mujeres el derecho al voto, a excluirlas de los espacios de decisión política, y casi todos parecían coincidir en que la mayoría de las mujeres españolas, o al menos buena parte de ellas, contribuirían a excluirlas de los espacios de representación. Frente a la opinión de Clara Campoamor ${ }^{6}$, que se mostraba partidaria de la aprobación del voto femenino, Victoria Kent (cuyo nombre se hizo tan popular que incluso aparecía en el famoso chotis "Pichi" que cantaba por entonces Celia Gámez) defendía que la mayoría de las mujeres españolas no había alcanzado esa conciencia y autonomía y que, como consecuencia de ello, el sufragio femenino favorecería a los grupos conservadores puesto que gran parte de las mujeres votarían lo que les dijese su marido o la Iglesia. Para comprender la magnitud real de este problema, pensemos que en el momento de la votación, muchos diputados de partidos progresistas se ausentaron, entre ellos la única mujer que, junto a Campoamor y Kent, había en el parlamento, Margarita Nelken, diputada del Partido Socialista, que se proclamaba feminista y era de hecho defensora de un feminismo mucho más avanzado que la mayoría de la mujeres de la época, pero que mostraba grandes reservas ante la aprobación del sufragio femenino por considerar que la mujer española no había alcanzado el suficiente nivel de

obligada a ser la mujer de excepción”, Elisabeth YOUNG-BRUEHL, Hannah Arendt, Valencia, Edicions Alfons el Magnànim, 1993, 350. Por esa razón estuvo a punto de rechazar la invitación de esa misma Universidad, en 1959, para ser profesora con rango de catedrática, cuando supo que, en el comunicado dirigido al New York Times, se destacaba el hecho de que era la primera mujer en recibir esa invitación (ibidem)

${ }^{6}$ Clara CAMPOAMOR, El voto femenino y yo. Mi pecado mortal, Madrid, Horas y Horas, 2006. 
autonomía, con lo que la libertad del voto femenino no sería tal. Como resultado de todo este problema, nos encontramos con la paradójica circunstancia de que en España el sufragio femenino, aprobado por un escaso margen de votos, sale adelante con el apoyo de buena parte de los diputados conservadores porque, de acuerdo con las objeciones que oponía Victoria Kent, consideraron que las mujeres votarían mayoritariamente según los criterios que les indicase la Iglesia y eso los favorecería en las urnas?

Además de la trascendencia de lo que se estaba considerando, esta problemática supuso también la ampliación del área de lo político y de lo politizable, haciendo entrar en la esfera de lo políticamente discutible (aunque sólo de manera parcial y bastante tangencialmente) unos objetos y una preocupaciones descartados o ignorados por la tradición política porque parecían corresponder a la esfera de lo privado, por mucho que en gran medida estos primeros pasos formasen parte de las luchas de la lógica más tradicional de la política, en algunos casos subordinados a instancias que, por su acción negativa, contribuían de manera muy considerable a la perpetuación de las relaciones sociales de dominación entre los sexos.

Probablemente uno de los casos más llamativos sea el de María Lejárraga, que ganó en las elecciones de 1933 un escaño como diputada del Partido Socialista, gran intelectual y una de las escritoras más prolíficas de la primera mitad del siglo, que muestra en su obra una enorme preocupación por la cuestión de la emancipación femenina y exhorta a las españolas a cambiar su situación de mujeres subyugadas, pero cuyo nombre no sólo no figura en historias o en manuales, sino que ni siquiera encabeza las propias obras ni la serie de tratados

\footnotetext{
7 "Gracias a ella [Margarita Nelken], a Clara Campoamor, a Matilde Huici y a otras mujeres de la época entré en contacto con las avanzadas ideas del feminismo. Eran abogadas y profesionales, seguramente las primeras en la historia de España, y decían lo mismo que yo pensaba de la independencia y de la libertad de las mujeres", Irene FALCÓN, Asalto a los cielos: mi vida junto a Pasionaria, Madrid, Temas de Hoy, 1996, 48. Y sobre el debate en torno al voto femenino, afirma: "Hay que recordar que las mujeres españolas no consquistaron ese derecho hasta las elecciones del año 1933, que ya está bien. En las generales de 1931 algunas pudieron ser candidatas, pero no votar. Yo me encontraba, como todas las mujeres progresistas, en un dilema. Por un lado, era lógico y justo que la mujer pudiera votar, y de hecho yo luchaba por el sufragio como podía, desde la prensa; pero, al mismo tiempo, sabía que era peligroso desde una perspectiva progresista, porque la mujer estaba bajo la influencia de la Iglesia, y sabía que iba a votar de forma reaccionaria. Era la gran polémica entre Clara Campoamor, que decía 'hay que dar el voto', y Victoria Kent (...) Después de tanto tiempo transcurrido, creo que Clara Campoamor tenía razón. A pesar de que aparentemente la mayoría de las mujeres iban a votar lo que dijera su marido o su padre o su confesor, había que lanzar a las mujeres, darles los derechos que les correspondían. Lanzarlas y, dentro de la lucha, las mujeres ya sabrían a quién tendrían que acabar votando. En fin, era un proceso duro al que había que llegar porque, si no, a las mujeres nunca se les daría el voto", ibidem, 83-84.
} 
feministas. El que aparece es el de su marido, Gregorio Martínez Sierra, nombre con el que firmaba sus producciones. Tuvieron que pasar muchos años, y ya muerto el que había sido su marido, para que afirmase en su libro de memorias ${ }^{8}$ que esas obras eran colectivas, escritas por ambos, Gregorio y María, en colaboración, y ni siquiera en ese momento se atrevió o quiso reconocer lo que confirman documentos y testimonios, es decir, que María era la única autora de la mayoría de las obras que se firmaron con el nombre de Gregorio Martínez Sierra.

Se trata de un ejemplo enormemente significativo: viviendo en Madrid, con una educación progresista, hija de médico y de una mujer de formación excepcional para la época, María Lejárraga es un caso claro de cómo en muchos casos las mujeres sólo podían ejercer poder o mostrar talento (y que les sea reconocido) por delegación (es decir, como eminencia grises). Ello obliga a la inversión de las apariencias, a la exigencia de que el hombre ocupe, aunque sea de cara al exterior, la posición dominante de la pareja en lo que respecta a estas cuestiones. Los motivos que, según expuso la propia María, la llevaron a actuar de esa forma y el hecho de que nunca reconociese que ella era la autora de las obras muestran a las claras la lógica paradójica de la dominación masculina y la sumisión femenina. Así, esta mujer dedicada a la política, escritora prolífica y autora de distintos tratados y conferencias que defendían los derechos de la mujer (aunque el que aparezca como autor y el que leía las conferencias fuese su marido) es una muestra evidente de las limitaciones de las posibilidades de pensamiento y de acción a las que se enfrentaban estas mujeres.

Es muy significativo el hecho de que se refiera a sus obras como a hijos y que recurra con frecuencia a la hora de referirse a ellas a la metáfora de la reproducción biológica ${ }^{9}$ En esa misma línea, asegura haber concebido y parido más hijos de los debidos, por deseo expreso de su marido ${ }^{10}$. Con esa alusión a la biología trata de justificar que apareciese sólo el nombre de su marido argumentando de manera más o menos explícita que el acto de creación es colectivo y hace falta padre y madre, y que en su caso el que era su marido tuvo gran importancia en su formación y toma de conciencia. En definitiva, parece decir que en el trabajo de producir sus obras su marido tuvo una importancia decisiva en su fecundación (cosa que puede resultar discutible si atendemos a ambas trayectorias y a las propias obras), mientras que a ella llevó a cabo la parte de la gestación y el parto. En este caso, además, y puesto que los 'hijos' salieron a la luz sólo con el nombre del padre, parece que el acto (típicamente femenino)

\footnotetext{
${ }^{8}$ María MARTÍNEZ SIERRA, Gregorio y yo: medio siglo de colaboración, Valencia, Pre-Textos, 2000.

${ }^{9}$ Ibidem, 75-76.

${ }^{10}$ Ibidem, 126.
} 
de gestación y parto se encuentra anulado en favor del trabajo (que aparecería como propiamente masculino) de la fecundación.

También estamos ante un ejemplo claro de cómo forman parte de lo masculino los actos oficiales y de representación (la propia María insiste en que esas gestiones las hacía su marido, responsable de los aspectos comerciales), mientras que las mujeres quedarían excluidas de los espacios públicos, y sometidas además a un trabajo de socialización que tendía a menoscabarlas y a toda la serie de expectativas colectivas a las que estaban enfrentadas. Esta última cuestión afectaba también de lleno a las mujeres parlamentarias, de las cuales varias eran, como Lejárraga, escritoras (Montseny y Nelken, por ejemplo, así como otras con una intensa actividad política, aunque no llegasen al parlamento: Irene Falcón, Carlota O'Neill...), y casi todas escribieron posteriormente sus memorias, algunas más o menos noveladas o poéticas. Todos esos testimonios son de gran ayuda para estudiar la problemática que estamos tratando, pues la literatura puede sin duda constituirse como representación lúcida del espacio social y ser un instrumento de primera magnitud para los estudios de género. No es extraño: el discurso literario no surge del vacío, sino que se nutre de las ideologías socialmente vigentes, las reorganiza en función de sus propias orientaciones y exigencias, las incorpora selectivamente y las reacuña conceptualmente al traducirlas al lenguaje en el que expresa sus propias preocupaciones.

Resulta llamativo cómo la afirmación de independencia intelectual o el alcanzar determinadas cotas de poder (aunque sean limitadas), que se traducen además de manera inevitable en unas manifestaciones corporales, tienen el efecto de hacer aparecer a una mujer como no 'femenina': pensemos en la anécdota de que un parlamentario, al incorporarse Margarita Nelken, comentó con intenciones claras que al fin había llegado una mujer al hemiciclo, cuando ya había otras dos (las propias posiciones sociales están sexuadas y son sexuantes ${ }^{11}$ ).

Este hecho nos indica lo que significaba para estas mujeres el hecho de ser en todo momento conscientes de su cuerpo, de estar siempre expuestas a la humillación o al ridículo, y, en definitiva, de la situación de la mujer como ser percibido, y percibido por la mirada masculina. Muchos de los datos o de las anécdotas que nos han llegado sobre estas políticas nos hablan de manera clara de lo que suponía el 'arte' de vivir en femenino y del buen comportamiento, corporal y moral, que llevaba consigo. Todo el trabajo de socialización tiende a

${ }_{11}$ Tras una de las intervenciones de Pasionaria en el Parlamento, otro diputado señaló que "ha hablado como un hombre, como el único hombre que ha hablado hoy en la Cámara", y algunos periodistas comentaron la vergüenza que suponía que una mujer hubiera acorralado y vencido a sus adversarios hombres (cf. Rafael CRUZ, Pasionaria. Dolores Ibárruri, bistoria y símbolo, Madrid, Biblioteca Nueva, 1999, 133). 
imponerles unos límites que conciernen al cuerpo (en lo que se refiere al vestir, por ejemplo, o a distintas costumbres asociadas a lo corporal), un aprendizaje de sumisión del cuerpo que está caracterizado socialmente de manera profunda.

Pensemos además en cómo la violencia simbólica ${ }^{12}$ se reforzaba con frecuencia combinando varias características distintivas (o estigmas, desde este punto de vista). Así, en el caso de Victoria Kent, por su opción sexual, o de Irene Falcón, culta, políglota, directora de una colección de libros de mujeres (inspirada en la colección que dirigía Federica Montseny en "La Novela Ideal") en la que se publicaron, entre otras, La técnica del amor, de Doris Langley Moore, La dama bolchevique, de Vera Imber, o Hypatía, de Dora Russell, que apareció con un prólogo de la propia Irene Falcón y que era una respuesta a un libro antifeminista, Lysistrata, de A. M. Ludovico, publicado previamente por la Revista de Occidente. Hija de padre judío de origen alemán, es fácil percibir ramalazos de antisemitismo en las críticas que se le dirigían (como ocurre también, por ejemplo, en el caso de Margarita Nelken, que unía a ese 'pecado original' el de ser una mujer atractiva ${ }^{13}$ ).

En el caso de estas mujeres que ocuparon una posición importante en la política española de esos años, habría además que reflexionar sobre el hecho llamativo de que en un porcentaje muy elevado son mujeres sin hombre. Pensemos, por ejemplo, en las tres diputadas en las primeras elecciones de la Segunda República, Campoamor, Kent y Nelken, las tres solteras. O en

\footnotetext{
${ }^{12}$ La noción de 'violencia simbólica' fue propuesta por Pierre Bourdieu que, en La dominación masculina, ofrece la siguiente definición: "Siempre he visto en la dominación masculina y en la manera como se ha impuesto y soportado, el mejor ejemplo de aquella sumisión paradójica, consecuencia de lo que llamo violencia simbólica, violencia amortiguada, insensible, e invisible para sus propias víctimas, que se ejerce esencialmente a través de los caminos puramente simbólicos de la comunicación y del conocimiento o, más exactamente, del desconocimiento, del reconocimiento o, en último término, del sentimiento. Esta relación social extraordinariamente común ofrece por tanto una ocasión privilegiada de entender la lógica de la dominación ejercida en nombre de un principio simbólico conocido y admitido tanto por el dominador como por el dominado, un idioma (o una manera de modularlo), un estilo de vida (o una manera de pensar, de hablar o de comportarse) y, más habitualmente, una característica distintiva, emblema o estigma, cuya mayor eficacia simbólica es la característica corporal absolutamente arbitraria e imprevisible", Pierre BOURDIEU, La dominación masculina, Barcelona, Anagrama, 2000, 11-12.

${ }^{13}$ Irene Falcón dice sobre Nelken en sus memorias: "Tenía muy mala fama, sobre todo entre sus compañeros periodistas más machistas, quienes malévolamente la apodaban 'el colchón de las redacciones' porque ella presumía de que tenía muchos hijos, cada uno de un padre distinto. Yo admiraba la audacia, la libertad y el criterio con que proclamaba su promiscuidad y su prolífica maternidad. La verdad es que todo aquello era pura fanfarria, porque cuando años más tarde la conocí en profundidad, al convertirse en colaboradora de la agencia de noticias AIMA, estaba casada con un marido estable y muy serio y sólo tenía una hija y un hijo", FALCÓN, op. cit., 47-48.
} 
Pasionaria $^{14}$, siempre vestida de negro, con ropa ancha, que evitaba que se le conociesen compañías masculinas (no hay más que pensar en el desarrollo y las consecuencias que tuvo el 'caso Antón' ${ }^{15}$ tanto para ella como para el propio Francisco Antón). Sin embargo, era sabido que Margarita Nelken era madre soltera o que Pasionaria estaba separada y tenía hijos. En el caso de las mujeres que ocuparon puestos de responsabilidad política, podría parecer que para que una mujer 'mandase' o tuviese cierto grado de poder sobre hombres, tendría que ser ella misma una mujer sin hombre (quizá porque de alguna manera se asume o se cree que los demás asumirían lo que tradicionalmente se asociaba a una mujer casada, es decir, que sobre ella 'manda' o tiene una gran influencia su marido, que a él debe lealtades y obediencia...). Y eso incluso cuando habría que estudiar detenidamente qué grado real de poder y de autoridad tenía cada una de ellas sobre hombres, puesto que es evidente que eran ellos los que seguían dominando el espacio público y el campo del poder, mientras que las mujeres permanecen entregadas fundamentalmente al espacio privado donde se perpetúa la lógica de la economía de los bienes simbólicos, o a extensiones de ese espacio, los llamados servicios sociales y educativos, o también en los universos de producción simbólica (espacio literario, artístico y periodístico, etc.). Sin duda no es gratuito el hecho de que, como antes hemos dicho, muchas de estas mujeres dedicadas a la política fuesen también escritoras o, aún más evidente, que muchos de los puestos que ocupaban fuesen una prolongación de los espacios domésticos, es decir, los servicios sociales (Federica Montseny fue ministra de Sanidad y Asistencia Social durante la Guerra Civil: es impensable que lo hubiese sido de Economía, por ejemplo, o probablemente de casi cualquier otro ministerio, salvo quizá el de Educación).

En este sentido, sería interesante analizar la diferencia entre estas mujeres de enorme presencia en la vida política española en estos años, siempre desde partidos socialistas, comunistas o anarquistas, y el papel que desempeñan las mujeres que adquieren notoriedad pero que pertenecen a partidos conservadores. La figura fundamental sería sin duda Pilar Primo de Rivera, hermana de José Antonio Primo de Rivera y presidenta desde 1934 de la Sección Femenina de Falange ${ }^{16}$. En

\footnotetext{
${ }^{14}$ Existen muchas biografías y estudios sobre Dolores Ibárruri, Pasionaria. Son de gran interés, por ejemplo, CRUZ, op. cit., y Manuel VÁZQUEZ MONTALBÁN, Pasionaria y los siete enanitos, Barcelona, DeBolsillo, 2005. Pasionaria relata su proceso de formación y el desarrollo de su carrera política en: Dolores IBÁRRURI, El único camino, Madrid, Castalia, 1992.

15 VÁZQUEZ MONTALBÁN, op. cit., 46-47 y 218-220. Dice Vázquez Montalbán que “cada vez que aparece la cuestión sexual en cualquier conversación con sus biógrafos o sucedáneos, Dolores reacciona con una pudibundez incomprensible", ibidem., 46.

${ }^{16}$ Puede consultarse Kathleen RICHMOND, Las mujeres en el fascismo español. La Sección Femenina de la Falange, 1934-1959, Madrid, Alianza Editorial, 2004.
} 
España, además, no podemos perder de vista el hecho de que Falange es un caso particular con respecto a los otros fascismos europeos por el peso de la Iglesia dentro de la organización. Naturalmente, defienden el papel tradicional de la mujer (es decir, la casa, entregada a los hijos...) pero también les exige nuevas obligaciones. Por ejemplo, hay una lealtad y una obligación que es pareja o incluso superior a la de la familia: la que deben a la patria y al movimiento (de hecho, tener hijos es una de las obligaciones más importantes que una mujer tendría hacia la patria). Otra de esas nuevas exigencias es la participación en organizaciones (la Sección Femenina, organizaciones benéficas....) que las saca al ámbito público aunque por supuesto siempre como guardianas de determinados valores.

Otro tema interesante que se nos abriría es el de los mitos nacionales femeninos (el caso de Pasionaria en España, por ejemplo, pero que podríamos remontar incluso a Juana de Arco, Marianne de Francia, Isabel y Victoria de Inglaterra, la Madre Rusia o a todas las representaciones del Estado o de la República como una mujer). La asociación parece clara: todos estos mitos nacionales son femeninos porque probablemente se pretende sugerir la idea de protección, cuidados, amor, fortaleza sacrificio, entrega, todo ese tipo de valores que tradicionalmente aparecen asociados a la figura de la madre.

En general, estos mitos tienen en común que se va imaginando la figura de estas mujeres como encarnación del pueblo, portadoras de una serie de virtudes (capacidad de sufrimiento, de sacrificio, de entrega a los demás...) coincidentes con las que, se suele decir también, representan o deberían representar (nombran el orden y llaman al orden) las cualidades de la maternidad. De este modo, se selecciona, resalta e imagina toda esa serie de características, esta vez concentradas en una sola persona; pensemos, por ejemplo, que con frecuencia se han equiparado las figuras de distintos mitos nacionales femeninos: "Se establecieron comparaciones con mujeres con una participación pública destacada en el pasado, y a las que se calificó también de heroínas. La figura de Dolores [ibárruri] equivalía a la de Rosalía de Castro, Mariana Pineda y Agustina de Aragón" ${ }^{\text {"17 }}$.

En el caso de Rosalía de Castro, otro mito nacional materno, una de las ideas que se encuentra con frecuencia en los estudios sobre su figura es la del énfasis de aquellos rasgos que la harían única ${ }^{18}$ : su singularidad (por ser una mujer escritora, por haber escrito en una lengua como el gallego en el momento en que ella lo

\footnotetext{
${ }^{17}$ CRUZ, op. cit., 241.

18 "El común denominador de la mayoría de los estudios sobre Rosalía de Castro es que parecen querer enfatizar aquellos rasgos que la hacen única, sin insertarla en un contexto más amplio", Elena SÁNCHEZ MORA, "Rosalía de Castro: ¿bachillera o ángel del hogar?", in Actas do Congreso internacional de estudios sobre Rosalía de Castro e o seu tempo, Tomo I, Santiago de Compostela, Consello da Cultura galega, Universidade de Santiago de Compostela, 1986, 251.
} 
hizo...) es un elemento necesario para la construcción de un mito como el suyo, así como el ser considerada una precursora (en realidad, en su caso, casi una madre que nutre, da vida y abre camino al iniciar la literatura moderna en lengua gallega). Mujer única, por tanto, sola, sentada en su banco de excepción, la misma excepcionalidad que encontramos en el resto de los mitos nacionales femeninos.

También redundarán todas esos textos que se le dedican sobre la simbología materna de Rosalía de Castro, estrechamente relacionada con el modelo popular, como relacionados se encuentran la insistencia terrícola, espectáculo simbólico de maternidad. Así, no falta la poesía en la que Rosalía equivale a la tierra y a Galicia. En cualquier caso, en los poemas quedan claras las bases de esa especie de trinidad metafísica (mujer, Galicia, madre) que acompaña su mito, como en general todos los mitos femeninos maternos; pensemos, de nuevo, en el mito de Pasionaria: todas las equivalencias anteriormente descritas se le pueden aplicar con sólo cambiar Galicia por España.

A partir sobre todo de la postguerra española y hasta la actualidad, se le dedican a Rosalía multitud de poemas en Galicia (especialmente de mano de mujeres poetas como Pura Vázquez, Xohana Torres, Luz Pozo Garza, entre otras muchas) en los que se desarrolla esa imagen materna arquetípica. Así, por ejemplo, Xaquina Trillo escribe en su poema "No adro de Bastabales", del libro Ceibos $^{19}$ (de 1980 y en el que dice literalmente que Rosalía fue madre (nai) para Galicia y escribe "Ela", es decir, ella, refiriéndose a Rosalía, con mayúscula):

Que Ela para Galiza foi, amiguiña, irmán e nai.

Tres cousas as milloriñas

tres cousas cóma non hai

Se le escriben incluso unas letanías en las que podría decirse que sustituye a la Virgen María: pensemos, de hecho, en el apelativo 'a Santiña' que con frecuencia se le da a Rosalía de Castro en Galicia, o en poemas como "Ladaíña a Rosalía de Castro", de Ernesto Guerra da Cal, con un estribillo que, recordando los rezos del rosario y como si se tratase de una auténtica letanía (ladaiña, en gallego), repite "Madre Rosalía, ruega por nosotros" ("Mai Rosalía, roga por nós"), además de llamarla "Nosa Senhora da Saùdade" ("Nuestra Señora de la Melancolía") y utilizar los símbolos de la paloma blanca, la estrella, la rosa, etc, que dentro de la simbología cristiana se utilizan para referirse a la Virgen María ${ }^{20}$.

\footnotetext{
${ }^{19}$ Xaquina TRILLO, Ceibos, Lugo, Ediciones Celta, 1980. Por citar otro ejemplo de los muchos posibles, dice Luz POZO GARZA en "Preguntas a Rosalía", que apareció en Concerto de outono, A Coruña, Edicións do Castro, 1981: "Ti me levas da man / á percura da táboa / nosa".

${ }^{20}$ Ernesto GUERRA DA CAL, Lúa de Alén-Mar: 1939-1958, Vigo, Galaxia, 1959, 21-22.
} 
También la música ha consolidado el mito, dedicándole discos o canciones y musicando textos suyos: no hay más que pensar en que "Negra sombra", el famoso poema de Rosalía de Castro que aparece en Follas novas, forma parte ya del folclore gallego.

Casi todo lo que llevamos dicho podría aplicarse también al caso de Pasionaria: desde 1936 hasta su muerte fue protagonista de innumerables poemas dedicados a cantar su figura materna, su mitología terrícola, sus cualidades excepcionales que la convertían en una mujer única. Miguel Hernández ("Una mujer que es una estepa sola", dice en el poema que le dedicó en Viento del pueblo, "mujer, España, madre en infinito", "mujer redimida y agrandada"), Alberti ("madre del sol de la mañana", "entraña del pueblo", "norte de nuestra reconquista,/ segura estrella salvadora,/ Pasionaria, la nueva aurora. ¡Es el Partido Comunista!", dice en el poema que le dedicó en Signos del día), Blas de Otero, Nicolás Guillén, Pablo Neruda, Vicente Huidobro y una larga nómina de poetas exaltaron su imagen y su figura de excepción. Tampoco fue ajena la música en ese proceso de consagración de su mito y de las características que lo acompañaban, haciendo buena la profecía del escritor y periodista Ilya Ehrenburg ("día llegará en que de esta mujer hablarán las canciones"). Así, por ejemplo, Marta Contreras puso música al poema "Pasionaria", de Nicolás Guillén, aunque probablemente el caso más conocido es el de "Veremos a Dolores", canción a la que dio voz Ana Belén y que entonó incluso en el multitudinario entierro de Dolores Ibárruri, tras la lectura por parte de Rafael Alberti del poema del que antes reproducíamos algunos versos.

Naturalmente, también existen mitos nacionales masculinos, pero presentan siempre unas características muy distintas a las que estamos señalando. En el caso de Galicia, por ejemplo, si la 'madre' es, como antes señalábamos, Rosalía de Castro, el 'padre' es sin duda Alfonso R. Castelao, el político más destacado de cuantos han defendido en ese territorio las ideas nacionalistas, además de teórico fundamental de ese movimiento con su Sempre en Galiza, figura mítica sin parangón en la Galicia de la transición y la democracia y referente simbólico omnipresente de reivindicación.

Podemos comparar, por ser enormemente significativos, los rituales funerarios de ambas figuras para tomar conciencia de las diferencias de su mito. Rosalía de Castro fue enterrada en el cementerio de Santa María de Adina, en la localidad de Padrón, y posteriormente, el 25 de mayo de 1891, concitando un respeto público unánime, sus restos fueron trasladados al Panteón de Gallegos Ilustres. Se celebraron, entre otros actos, honras fúnebres y una misa en la que réquiem era una obra de Domingo Murguía, abuelo materno de su marido. Fue, en definitiva, un ritual funerario con amplias resonancias sociales pero también políticas e ideológicas, un hecho muy frecuente en el mundo contemporáneo. 
Sin duda, es grande el contraste entre el ritual funerario de Rosalía (a finales del siglo XIX y tratándose de una figura amable, materna, reivindicada de un modo u otro por todos los grupos y tendencias sin que resulte incómoda para nadie) y el de Castelao: fallecido en Buenos Aires en 1950, su muerte tuvo una gran repercusión en las comunidades del exilio y su entierro constituyó un gran acto ritual y claramente político, que incluyó banderas, música, himnos, discursos... Fue, en efecto, un ritual del nacionalismo gallego pero también de todo el exilio republicano, un hecho posible al encontrarse en unas circunstancias históricas tan excepcionales como los largos años de dictadura y exilio.

El 'segundo funeral' de Castelao, es decir, el traslado de sus restos mortales a Galicia en los años ochenta, fue en cierto modo muy distinto: de directa reivindicación nacionalista y ocurrido tras una agria polémica, incluyó una buena dosis de violencia entre la policía y los asistentes, que consideraban que se estaba traicionando la memoria del difunto.

De lo que no cabe duda es de que los dos, Rosalía y Castelao, en su traslado al Panteón de Gallegos Ilustres, tuvieron su propio conjunto de significados políticos. Y son rituales que se repiten y siguen cumpliendo su objetivo a día de hoy: cada 17 de mayo, Día das Letras Galegas, se hace en la tumba de Rosalía de Castro una ofrenda floral acompañada por distintos actos (conferencias sobre la lengua y la literatura gallegas, exposiciones, homenajes...) y que sigue teniendo unas connotaciones sociales y políticas claras. En ese sentido, continúa siendo un ritual que cumple su función de reforzar una identidad colectiva al homenajear a la 'madre'.

También siguen cumpliendo su objetivo los rituales fúnebres que se ofrecen a Castelao: la ofrenda floral que cada año hacen ante su tumba los partidos y líderes nacionalistas el 25 de julio (Día de la Patria Galega, de Galicia o Nacional de Galicia), con todo el despliegue de símbolos, sigue siendo hoy en día uno de los actos de reivindicación fundamentales del nacionalismo en Galicia.

Como puede verse, Galicia tiene una 'madre', Rosalía de Castro, y un 'padre', Castelao. Ella es una figura dulce, amable, maternal, denotadora de la 'morriña' gallega, sujeta a muchos intereses ideológicos pero invocada por todo el mundo de cualquier signo político y por tanto también de devoción unánime; él, en cambio, es una figura de connotaciones mucho más fuertes y ásperas, de directa reivindicación política. Así, en los procesos de sublimación y mitificación de ambas figuras, la simbología que los rodea da cuenta de manera estricta de hasta qué punto aparece claramente respetada la división sexual también en materia de mitologías nacionales. 